SHORT COMMUNICATION

\title{
Acute and chronic toxicity of four commonly used agricultural pesticides on the Asian common toad, Bufo melanostictus Schneider
}

\author{
U.A. Jayawardena ${ }^{1,2}$, A.N. Navaratne ${ }^{3}$, P.H. Amerasinghe ${ }^{4}$ and R.S. Rajakaruna ${ }^{1 *}$ \\ ${ }^{1}$ Department of Zoology, Faculty of Science, University of Peradeniya, Peradeniya. \\ ${ }^{2}$ Postgraduate Institute of Science, University of Peradeniya, Peradeniya. \\ ${ }^{3}$ Department of Chemistry, Faculty of Science, University of Peradeniya, Peradeniya. \\ ${ }^{4}$ International Water Management Institute, C/o ICRISAT, Patancheru, Hyderabad, Andhra Pradesh, India.
}

Revised: 15 December 2010 ; Accepted: 17 December 2010

\begin{abstract}
Laboratory and field studies provide evidence that pesticides may play a role in population declines, range reductions and species extinctions of amphibians. The present study examined the acute and chronic toxicity of four commonly used agricultural pesticides, chlorpyrifos, dimethoate, glyphosate and propanil on the survival, growth and development of malformations in the Asian common toad, Bufo melanostictus, under laboratory conditions. The 48 hour $\mathrm{LC}_{50}$ values of the chemicals were within the Pesticide Area Network (PAN) specified limits, except for propanil, which was less than the PAN specified value. Acute exposure to high concentrations of propanil may have a high direct toxic effect on the Asian common toad. The survival of the tadpoles with chronic exposure to ecologically relevant doses of the four pesticides was significantly reduced (survival in chlorpyrifos $39 \%$, dimethoate $41 \%$, glyphosate $36 \%$ and propanil $40 \%$ in the highest concentration) than in the control group (93\%). Exposed tadpoles took more time to metamorphose but were larger in size than the control tadpoles. They also developed malformations at high frequencies (chlorpyrifos 30\%, dimethoate $25 \%$, glyphosate $35 \%$ and propanil $15 \%$ in the highest concentration). Malformations were mainly axial, including kyphosis (hunched back) and scoliosis (curvature) while skin ulcers and oedemas were also observed. Severe limb malformations such as extra or missing limbs as reported for other species of amphibians exposed to pesticides were not observed in the Asian common toad. None of the tadpoles in the control group had any malformations. Glyphosate exposed metamorphs recorded the highest mortality and malformations at high concentrations $(1.0 \mathrm{ppm})$. However, a profound toxic effect was observed in chlorpyrifos exposed group even at low concentrations $(0.1 \mathrm{ppm})$. The study shows that exposure to commonly used agrochemicals poses serious risk to amphibians in Sri Lanka and highlights the importance of investigating the level of agricultural pesticides in freshwater ecosystems and their effect on non-target organisms.
\end{abstract}

Keywords: Bufo melanostictus, chlorpyrifos, dimethoate, glyphosate, malformations, propanil.

\section{INTRODUCTION}

Amphibians are the most threatened of all vertebrate taxa in the world with more than $32 \%$ of the species threatened and more than $43 \%$ experiencing some form of population decline (Stuart et al., 2004). A number of factors may affect amphibian populations, including habitat degradation, diseases and pathogens, invasive predators and competitors, depleted ozone and the presence of pollutants (Blaustein \& Wake, 1995; Alford \& Richards, 1999; Cowman \& Mazanti, 2000; Sparling et al., 2001; Blaustein et al., 2003). Pesticides widely used in agriculture have received the attention of many ecologists to study their toxicity to non-target organisms. Pesticides can have many adverse effects on amphibians, which can be direct or indirect at lethal or sublethal level. The sublethal effects to pesticides on amphibians include abnormal growth, development and behaviour, which in turn may alter susceptibility to predation and competition, and decrease reproductive success (Bridges, 1999; Sparling, 2003; Boone \& Semlitsch, 2002; Reylea, 2005). The effect of pesticides have been widely studied in ranids such as the northern leopard frog (Rana pipiens), the mink frog ( $R$. septentironalis), the green frog $(R$. clamitans), the bullfrogs ( $R$. cateasbeiana) and the foot hill yellow legged frog ( $R$. boylii) (Berril et al., 1994; Bridges \& Semlitsch, 2000; Christin et al., 2003; Hayes et al., 2003; Sparling \& Fellers, 2007; 2009). Hind limb deformities in wild caught green frogs, northern leopard frog, American toad (Bufo americanus) and bullfrogs

\footnotetext{
${ }^{*}$ Corresponding author (rupikar@pdn.ac.lk)
} 
have been observed in pesticide contaminated areas in the St. Lawrence River valley of Quebec, Canada (Ouellet et al., 1997).

In Sri Lanka, 103 species of anurans and caecillians have been described so far (Manamendra-Arachchi \& Pethiyagoda, 2006), which counts for $2 \%$ of the world's known anuran species (IUCN, 2006). An assessment completed in 2004 revealed that a total of 34 species of amphibians are known to have become extinct in the world and most of them belong to Sri Lankan amphibian fauna (Manamendra-Arachchi \& Pethiyagoda, 2006; Meegaskumbura \& Manamendra-Arachchi, 2005). The exact causes of this amphibian crisis or the factors threatening Sri Lankan amphibian populations are not yet identified. Occurrence of malformations in local amphibian populations has been observed in protected areas (Rajakaruna et al., 2007) and subsequent laboratory studies have provided evidence that a larval stage of a digenetic trematode may be responsible for high mortality and malformations (Rajakaruna et al., 2008; Jayawardena et al., 2010). A recent laboratory study provides evidence that pesticides may play a role in amphibian declines, reporting high mortality and malformation in the common hourglass tree frog, Polypedates cruciger exposed to pesticides (Jayawardena et al., 2010).

A large amount of agricultural pesticides are used in paddy, coconut and other crops in Sri Lanka and the run-off carries pesticides that might affect aquatic stages of amphibians directly (Pethiyagoda \& ManamendraArachchi, 1998). The present study explores the acute and chronic effects of four commonly used agrochemicals on the Asian common toad, Bufo melanostictus under laboratory conditions. The Asian common toad has an island-wide distribution associated with human habitats and is known to have expanded its natural ranges and established a higher relative dominance following habitat disturbances (Manamendra-Arachchi \& Pethiyagoda, 2006). It is known to be less sensitive to the perturbations in the environment and hence is an ideal amphibian species to study the effect of pesticides.

\section{METHODS AND MATERIALS}

Egg strands of newly spawned B. melanostictus were collected from the Peradeniya University Park and were brought to the laboratory. The eggs were placed in a glass trough containing dechlorinated tap water. Emergent tadpoles from four clutches were used in the study. Tadpoles were fed with ground commercial fish feed three times a day.

Commercial formulations of four commonly used agricultural pesticides including two organophosphorous insecticides, chlorpyrifos and dimethoate and two herbicides, glyphosate and propanil were used. Active ingredient of these pesticides has been diluted in different solvents/surfactants. Commercially available chlorpyrifos (Lorbosan EC $40^{\circledR}$ or Pattas ${ }^{\circledR}$ ) is dissolved in xylene $(1,2,4$-Trimethyl benzene) and is diluted in water $(20-30 \mathrm{~mL} / 10 \mathrm{~L}$, depending on the target pest) before applying to the field (4 - $8 \mathrm{~L} / \mathrm{ha})$. Dimethoate (Dimethoate EC $40^{\circledR}$ ) is dissolved in water and, before application in the field, is dissolved in water once again $(20-40 \mathrm{~mL} / 10 \mathrm{~L}$, depending on the target pest) and applied at $4-8 \mathrm{~L} /$ ha depending on the extent of the pest attack. Commercially available glyphosate, known as Roundup ${ }^{\circledR}$ or Glyphosate ${ }^{\circledR}$, is a combination of glyphosate and the surfactant, polyoxyethylene amine (POEA) and is applied after dissolving in water (i.e. for coconut plantations $1.44 \mathrm{~kg} / \mathrm{ha}$ ). Propanil $\left(3,4\right.$ - dichloropropionanilide or 3,4 $\left.\mathrm{DPA}^{\circledR}\right)$, dissolved in organic solvents such as cyclohexanone and petroleum solvents, is one of the most common herbicides used in paddy fields in the dry zone of Sri Lanka.

Samples of commercial formulations of the four test pesticides were obtained from the Pesticide Registrar's Office, Peradeniya. The pesticides used in this study are referred to based on the active ingredient (chlorpyrifos, dimethoate, glyphosate and propanil) throughout the manuscript.

Five days post-hatch tadpoles (Gosner stage 25-26; Gosner, 1960) were exposed to high concentration of the four pesticides for $48 \mathrm{~h}$. After a preliminary range finding exposure, a dilution series of 2.5, 2.0, 1.5, 1.0 and 0.5 ppm was used for chlorpyrifos and propanil, and a higher series of $25.0,18.75,15.00,11.25$ and 9.50 ppm was used for dimethoate and glyphosate. The pesticides were diluted in dechlorinated tap water, which was also used as the control medium. Lethal concentrations, $\mathrm{LC}_{50}, \mathrm{LC}_{10}$ and $\mathrm{LC}_{90}$ (concentration at which $50 \%, 10 \%$ and $90 \%$ of tadpoles die, respectively) of the four pesticides were determined. Tadpoles from three clutches were used in the acute exposure studies. Tadpoles were placed in glass tanks (measuring $15 \times 15 \times 25 \mathrm{~cm}$ ) containing $2 \mathrm{~L}$ of the test solution and the mortality at $48 \mathrm{~h}$ after exposure was recorded.

Five days post-hatch tadpoles (Gosner stage 25-26; Gosner 1960) were exposed to ecologically relevant concentrations of the four pesticides in similar glass tanks containing $2 \mathrm{~L}$ of the test solution. The tadpoles were exposed to a concentration series of the pesticide similar to the concentrations found in the field. Concentration series of chlorpyrifos was prepared as 
$0.05,0.10,0.25$ and $0.5 \mathrm{ppm}$ based on previous reports (Moore et al., 1998; Mazanti et al., 2003). Chlorpyrifos concentrations in small water bodies adjacent to agricultural lands have been estimated to be in the range of $0.1 \mathrm{ppm}$ up to $1.0 \mathrm{ppm}$ (Moore et al., 1998; Mazanti et al., 2003). Concentration series for dimethoate, glyphosate and propanil were $0.25,0.50,0.75$ and 1.00 ppm. Information from the Pesticide Registrar Office and a recent study on glyphosate concentrations in the field reported as $10 \mathrm{ppm}$ in well water (Navaratne et al., 2009), were considered in preparing the ecologically relevant concentration series of the pesticides. Tests were initiated with 20 tadpoles per tank, exposing them to test concentrations of each pesticide and a control containing dechlorinated tap water. Dechlorinated tap water was used to dilute the test chemicals. The tadpoles were fed with commercial fish feed. Considering the rate of degradation of the chemicals in water and minimizing the stress due to extensive handling of tadpoles, the medium in the tanks was renewed weekly. Survival of the tadpoles was recorded daily until they underwent metamorphosis. Snout-vent length (SVL) of the tadpoles was measured to the nearest $0.01 \mathrm{~cm}$ using a digital vernier caliper and the body weight to the nearest $0.001 \mathrm{~g}$ was measured at metamorphosis using an analytical balance. The time required for forelimb emergence of half the number of tadpoles in each treatment $\left(\mathrm{TE}_{50}\right)$ was also recorded. Exposure was repeated using tadpoles from three different egg clutches. All the tanks were kept at room temperature with daytime temperature varying between $27-31{ }^{\circ} \mathrm{C}$ under a natural photoperiod of approximately $12: 12 \mathrm{~h}$.

Malformations were recorded at $10 \mathrm{~d}$ and $30 \mathrm{~d}$ posthatch (Gosner stages 27 and 31) and at metamorphosis. The percentage malformation was calculated as the number of malformed individuals at a given age divided by the initial number of tadpoles. The dead malformed individuals were also included in calculations.

At metamorphosis, all the malformed individuals were anesthetized (using tricaine methane sulfonate MS-222) and preserved in 5\% formalin. Laboratory rearing of the tadpoles and anesthetizing and killing of the malformed amphibians were carried out according to the protocols approved by the Canadian Council on Animal Care (1993). Malformations were categorized using the Field Guide to Malformations of Frogs and Toads (Meteyer, 2000).

The LC values of the pesticides were calculated using the EPA Probit Analysis Programme Version 1.5 (EPA, 2006) with the pooled data from three egg clutches. Results of the pesticide exposure at ecologically relevant doses were analysed using MINITAB 14.0 for Windows. An $F$-test showed that at the 0.05 significance level, the variance of the data from three clutches could not be ruled out to be different and hence the data were pooled and analysed. The individual effect of concentration on the survival of the tadpoles was analysed using a chi-square test. A correlation analysis was performed to test the relationship of survival, growth parameters (body weight, SVL and $\mathrm{TE}_{50}$ values) and percentage malformations with the concentrations of each chemical. The effect of each pesticide on growth parameters was analysed using oneway ANOVA. The differences in growth parameters and malformations among the four pesticides were compared using an analysis of co-variance (ANCOVA).

\section{RESULTS}

The 48 hour $\mathrm{LC}_{50}$ values of $B$. melanostictus for the four pesticides, chlorpyrifos, dimethoate, glyphosate and propanil are given in Table $1 . \mathrm{LC}_{90}$ and $\mathrm{LC}_{10}$ values were also reported with $95 \%$ confidence interval (CI) limits. The highest $\mathrm{LC}_{50}$ value was reported for glyphosate (45.94 ppm) and the lowest value for propanil (1.46 ppm; Table 1).

Tadpoles exposed to the four pesticides at ecologically relevant concentrations showed a decrease in survival, differences in growth pattern compared to the control and they also developed malformations.

The percentage survival of the exposed metamorphs was reduced compared to that of the control group (93\%; Table 2). At the highest concentration of the pesticide (chlorpyrifos $0.5 \mathrm{ppm}$ and $1.0 \mathrm{ppm}$ for others) glyphosate recorded the lowest survival rate $(36 \%)$ followed by chlorpyrifos (39\%) with proponil and dimethoate showing $40 \%$ and $41 \%$ survival, respectively (Table 2). The decrease in survival in exposed groups was significantly high in all four pesticides at all four concentrations compared to the control group (Chi square test, $\mathrm{p}<0.05$; Table 2). Survival decreased with

Table 1: The 48 hour lethal concentration (at 95\% CI) of the four pesticides at five days post- hatch tadpoles of $B$. melanostictus

\begin{tabular}{lccc}
\hline Pesticide & $\mathrm{LC}_{10}(\mathrm{ppm})$ & $\mathrm{LC}_{50}(\mathrm{ppm})$ & $\mathrm{LC}_{90}(\mathrm{ppm})$ \\
\hline Chlorpyrifos & 1.41 & 1.47 & 2.11 \\
Dimethoate & 6.04 & 8.89 & 13.09 \\
Glyphosate & 27.91 & 45.94 & 75.64 \\
Propanil & 0.95 & 1.46 & 2.25 \\
\hline
\end{tabular}

ppm $=$ parts per million 
Table 2: Percentage survival of B. melanostictus tadpoles and metamorphs exposed to four pesticides at different concentrations

\begin{tabular}{|c|c|c|c|c|}
\hline \multirow[t]{2}{*}{ Pesticide } & \multirow{2}{*}{$\begin{array}{l}\text { Exposure } \\
\text { level (ppm) }\end{array}$} & \multicolumn{3}{|c|}{ Percentage survival (\%) } \\
\hline & & $\begin{array}{l}10 \text { days post-hatch } \\
\text { tadpoles }(p)\end{array}$ & $\begin{array}{l}30 \text { days post-hatch } \\
\text { tadpoles (p) }\end{array}$ & $\begin{array}{c}\text { Metamorphs } \\
\text { (p) }\end{array}$ \\
\hline \multirow[t]{4}{*}{ Chlorpyrifos } & 0.05 & $70(0.000)$ & $65(0.000)$ & $59(0.000)$ \\
\hline & 0.10 & $59(0.000)$ & $54(0.000)$ & $43(0.000)$ \\
\hline & 0.25 & $51(0.002)$ & $46(0.001)$ & $40(0.001)$ \\
\hline & 0.50 & $50(0.008)$ & $44(0.004)$ & $39(0.008)$ \\
\hline \multirow[t]{4}{*}{ Dimethoate } & 0.25 & $65(0.000)$ & $60(0.000)$ & $56(0.000)$ \\
\hline & 0.50 & $61(0.002)$ & $55(0.001)$ & $51(0.001)$ \\
\hline & 0.75 & $59(0.002)$ & $56(0.001)$ & $48(0.001)$ \\
\hline & 1.00 & $50(0.004)$ & $44(0.002)$ & $41(0.003)$ \\
\hline \multirow[t]{4}{*}{ Glyphosate } & 0.25 & $56(0.001)$ & $51(0.000)$ & $50(0.000)$ \\
\hline & 0.50 & $61(0.001)$ & $56(0.000)$ & $51(0.000)$ \\
\hline & 0.75 & $55(0.002)$ & $46(0.001)$ & $44(0.000)$ \\
\hline & 1.00 & $54(0.001)$ & $44(0.000)$ & $36(0.000)$ \\
\hline \multirow[t]{4}{*}{ Propanil } & 0.25 & $64(0.002)$ & $56(0.000)$ & $50(0.001)$ \\
\hline & 0.50 & $51(0.001)$ & $44(0.000)$ & $39(0.001)$ \\
\hline & 0.75 & $56(0.000)$ & $43(0.000)$ & $39(0.001)$ \\
\hline & 1.00 & $58(0.004)$ & $49(0.001)$ & $40(0.001)$ \\
\hline Control & 0 & 100 & 99 & 93 \\
\hline
\end{tabular}

ppm $=$ parts per million

Table 3: Comparisons of mean snout-vent length (SVL) and mean body weight of B. melanostictus metamorphs exposed to ecologically relevant concentrations of the four pesticides with those of the control group using one-way ANOVA

\begin{tabular}{|c|c|c|c|c|c|}
\hline Pesticide & $\begin{array}{l}\text { Exposure } \\
\text { level (ppm) }\end{array}$ & $\begin{array}{l}\text { Mean SVL } \\
\pm \mathrm{SD}(\mathrm{cm})\end{array}$ & $\mathrm{F}$ & $\begin{array}{l}\text { Mean weight } \\
\pm \mathrm{SD}(\mathrm{g})\end{array}$ & $\mathrm{F}$ \\
\hline \multirow{4}{*}{ Chlorpyrifos } & 0.05 & $0.76 \pm 0.05$ & 192.24 & $0.069 \pm 0.02$ & 63.22 \\
\hline & 0.10 & $0.81 \pm 0.05$ & 240.98 & $0.071 \pm 0.02$ & 132.58 \\
\hline & 0.25 & $0.92 \pm 0.08$ & 213.65 & $0.086 \pm 0.02$ & 125.74 \\
\hline & 0.50 & $1.09 \pm 0.01$ & 387.16 & $0.108 \pm 0.02$ & 166.50 \\
\hline \multirow[t]{4}{*}{ Dimethoate } & 0.25 & $0.71 \pm 0.00$ & 67.16 & $0.061 \pm 0.01$ & 15.26 \\
\hline & 0.50 & $0.78 \pm 0.07$ & 78.82 & $0.067 \pm 0.01$ & 28.11 \\
\hline & 0.75 & $0.81 \pm 0.07$ & 95.66 & $0.079 \pm 0.01$ & 37.30 \\
\hline & 1.00 & $0.81 \pm 0.13$ & 177.46 & $0.083 \pm 0.01$ & 56.85 \\
\hline \multirow[t]{4}{*}{ Glyphosate } & 0.25 & $0.77 \pm 0.04$ & 79.67 & $0.060 \pm 0.01$ & 27.94 \\
\hline & 0.50 & $0.76 \pm 0.02$ & 137.82 & $0.068 \pm 0.02$ & 19.45 \\
\hline & 0.75 & $0.93 \pm 0.04$ & 112.39 & $0.081 \pm 0.00$ & 30.70 \\
\hline & 1.00 & $1.12 \pm 0.08$ & 180.63 & $0.083 \pm 0.01$ & 47.79 \\
\hline \multirow[t]{4}{*}{ Propanil } & 0.25 & $0.78 \pm 0.01$ & 91.51 & $0.060 \pm 0.00$ & 31.31 \\
\hline & 0.50 & $0.78 \pm 0.05$ & 125.79 & $0.068 \pm 0.01$ & 42.50 \\
\hline & 0.75 & $0.82 \pm 0.05$ & 146.99 & $0.072 \pm 0.01$ & 59.53 \\
\hline & 1.00 & $0.98 \pm 0.03$ & 199.38 & $0.073 \pm 0.01$ & 39.56 \\
\hline Control & 0 & $0.72 \pm 0.04$ & - & $0.054 \pm 0.00$ & - \\
\hline
\end{tabular}

$\mathrm{df}=1 ; \mathrm{p}<0.001$ for all the comparisons $\mathrm{SD}=$ standard deviation 
increasing concentration of pesticides (Table 2), but this relationship was significant only in the chlorpyrifos treated group (Pearson Correlation, $\mathrm{r}=-0.879, \mathrm{p}=0.05$ ).
In the other three pesticides survival decreased with the concentration but the relationship was not statistically significant (Pearson Correlation, $\mathrm{p}>0.05$ ).

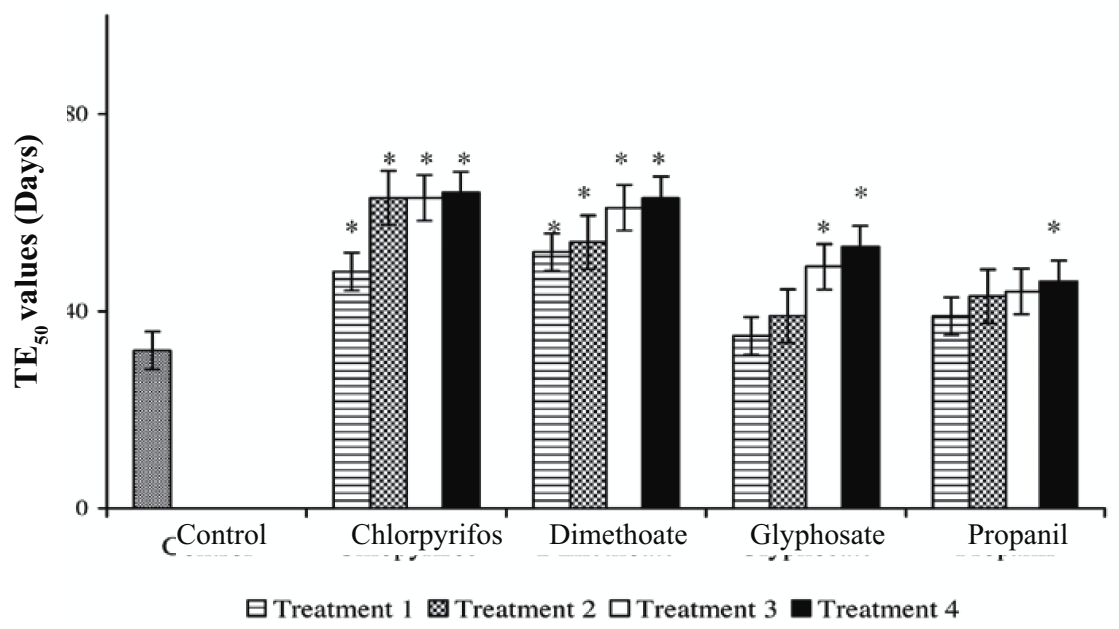

Figure 1: Average $\mathrm{TE}_{50}$ (time required for forelimb emergence in half the number of tadpoles) values of tadpoles of B. melanostictus exposed to chlorpyrifos, dimethoate, glyphosate and propanil at different concentrations (exposure levels are given as Treatment $1=0.05 \mathrm{ppm}, 2=0.10 \mathrm{ppm}, 3=0.25 \mathrm{ppm}$ and $4=0.5 \mathrm{ppm}$ for chlorpyrifos, and Treatment $1=0.25 \mathrm{ppm}, 2=0.50 \mathrm{ppm}, 3=0.75 \mathrm{ppm}$ and $4=1.0 \mathrm{ppm}$ for other chemicals). *Represents the $\mathrm{TE}_{50}$ values significant at $\mathrm{p}<0.05$ (ANOVA) compared to the control

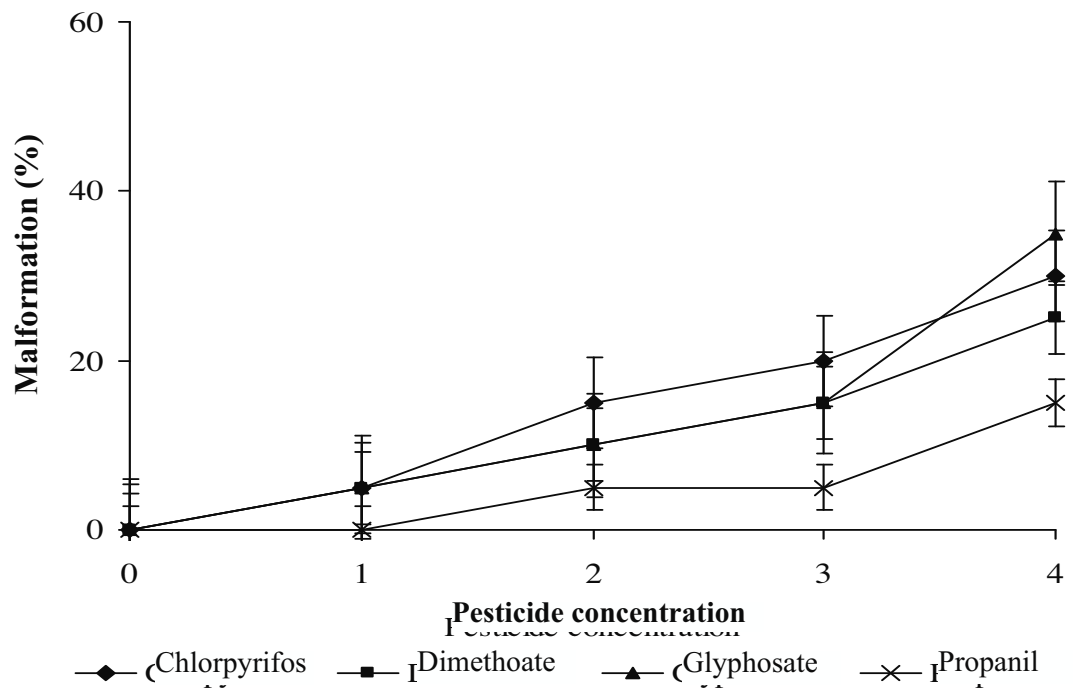

Figure 2: Percentage incidence of malformation observed in 10 days post-hatch tadpoles of B. melanostictus exposed to different concentrations of the four pesticides. $0=$ control, $1-4$ denotes the increasing order of the pesticide dose $(1=0.05 \mathrm{ppm}, 2=0.1 \mathrm{ppm}, 3=0.25 \mathrm{ppm}$ and $4=0.5 \mathrm{ppm}$ for chlorpyrifos, and $1=0.25 \mathrm{ppm}$, $2=0.5 \mathrm{ppm}, 3=0.75 \mathrm{ppm}$ and $4=1.0 \mathrm{ppm}$ for other pesticides). 


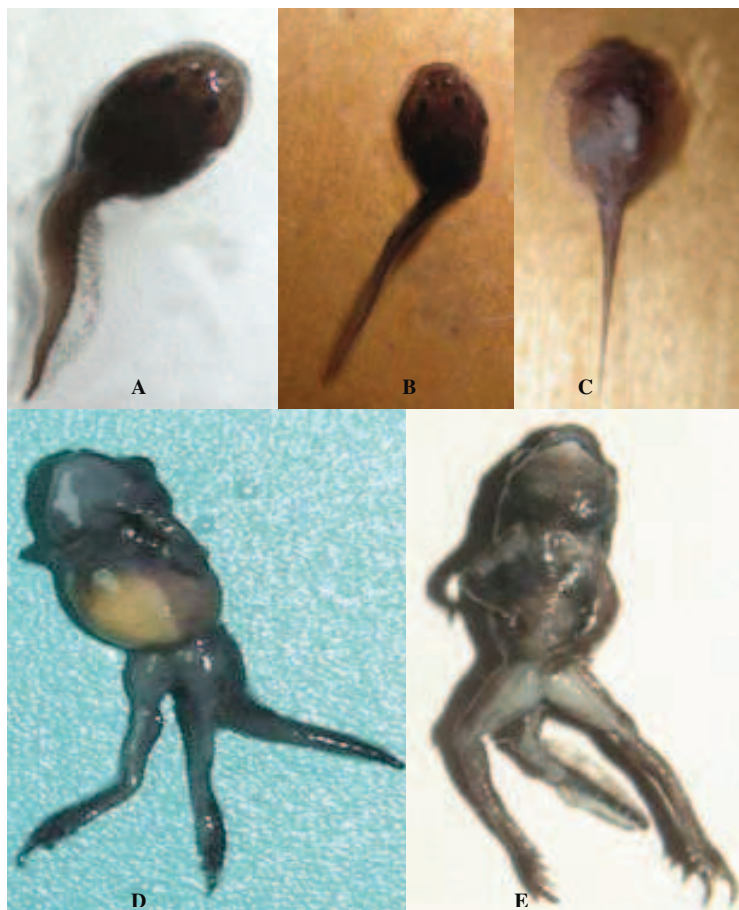

Figure 3: Composite of malformations observed in B. melanostictus exposed to pesticides: A) curvature in the vertebral column (scoliosis), B) hunched back (kyphosis), C) oedema in early stage tadpoles, D) ulcer on the underside of the body, and E) kyphosis in late stage tadpoles

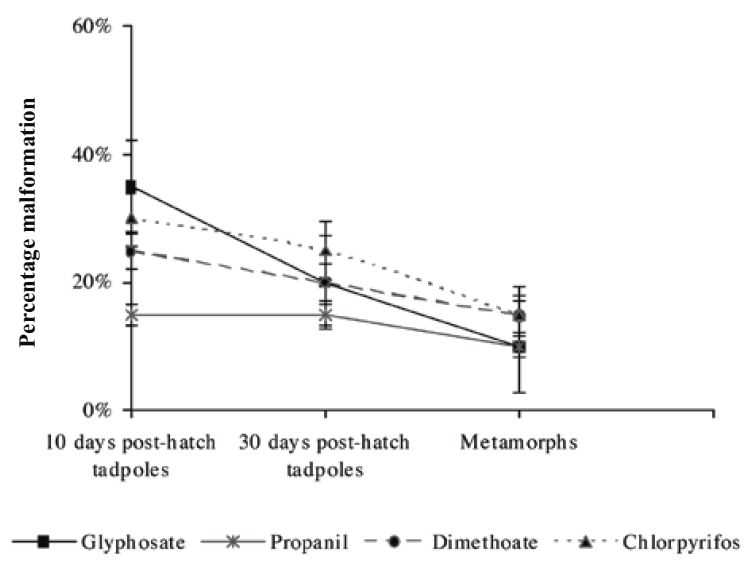

Figure 4: Percentage incidence of malformations at 10 days and 30 days post-hatch tadpoles and metamorphs of $B$. melanostictus exposed to the highest concentration of the pesticide $(0.5$ ppm for chlorpyrifos and $1.0 \mathrm{ppm}$ for dimethoate, glyphosate and propanil). The percentage malformation was calculated as the number of abnormal individuals (including the dead abnormal ones) at a given age divided by the initial number of tadpoles.
Individuals exposed to the pesticides took more time to metamorphose while showing increases in the growth parameters ( $\mathrm{SVL}$, body weight and $\mathrm{TE}_{50}$ ) compared to the control group (Table 3; Figure 1). Exposed metamorphs were larger than the control tadpoles and showed a significantly high enhancement in growth in all treatments (one way ANOVA, $\mathrm{p}<0.05$; Table 3). The SVL almost doubled in the tadpoles exposed to $1 \mathrm{ppm}$ compared to the control tadpoles (one way ANOVA, $F_{1,145}=180.63$, $\mathrm{p}<0.001)$. Moreover, growth of the metamorphosed individuals was also affected significantly by the pesticide type (ANCOVA, $\mathrm{p}<0.05$ ) with chlorpyrifos having the most profound effect followed by glyphosate. The increase in growth was positively correlated with increasing concentration of the pesticides, and the correlation between pesticide concentration and both SVL and weight measurements were significant for all the pesticides (Pearson Correlation, $\mathrm{p}<0.05$ ).

The average $\mathrm{TE}_{50}$ value for $B$. melanostictus was 32 days (range 28- 34 days) in the control, while in exposed groups it exceeded 70 days (range 58-73 days) with chlorpyrifos recording the highest value of 73 days (Figure 1). This lengthening of development period was significantly high for chlorpyrifos and dimethoate exposed groups for all concentrations tested (one way ANOVA, $\mathrm{p}<0.05$; Figure 1). In the glyphosate treated group significant lengthening of the development period was observed with $0.75 \mathrm{ppm}$ (one way ANOVA, $F_{1,6}=$ $148.86, \mathrm{p}<0.001$ ) and $1.00 \mathrm{ppm}$ (one way ANOVA, $F_{1}$, $6=201.57, \mathrm{p}<0.001)$ compared to the control. However, in propanil treated tadpoles a significant difference was observed only in $1.00 \mathrm{ppm}$ treatment (one way ANOVA, $\left.F_{1,6}=18.16, \mathrm{p}<0.01\right)$ compared to the control.

Varying percentages of malformations were observed in tadpoles and metamorphs in all the treated groups whereas no malformations were observed in the control group (Figure 2). The highest percentage malformation was recorded in the tadpoles exposed to $1 \mathrm{ppm}$ glyphosate (35\%; Figure 2). The percentage malformation positively correlated with the concentration of the pesticides and a significant relationship was observed in chlopyrifos and dimethoate exposed groups (Pearson Correlation, chlorpyrifos; $\mathrm{r}=0.992, p=0.008$, dimethoate; $\mathrm{r}=0.983$, $p=0.017$, respectively).

Malformations were mainly seen in the spine such as hunched back (kyphosis) and curvature (scoliosis) while oedemas and skin ulcers were also observed (Figure 3). Percentage malformations increased with increasing concentration of the pesticide. During metamorphosis some of the malformations disappeared, especially those in the tail region with the resorption of tail. Hence, the percentage malformation decreased with age (Figure 4). 


\section{DISCUSSION}

This study shows that the tested concentrations of commonly used pesticides such as chlopyrifos, dimethoate, glyphosate and propanil have a significant effect on the survival and growth of the common toad. Exposure to pesticides also induced malformations in tadpoles and metamorphs. Based on $\mathrm{LC}_{50}$ values assigned to most sensitive (crabs, mayfly larva, etc.) and least sensitive (trout, amphibians, small mammals, etc.) animal groups, chlopyrifos and dimethoate are classified as moderately toxic insecticides $(0.10-10 \mathrm{ppm})$ while glyphosate and propanil are classified as slightly toxic herbicides (10-100 ppm; Kegley, 2007). The 48 hour LC ${ }_{50}$ values for $B$. melanostictus were within PAN (Pesticide Area Network) specified limits for all the chemicals except for propanil. The $\mathrm{LC}_{50}$ values of propanil for $B$. melanostictus $(1.46 \mathrm{ppm})$ was lower than PAN reported values (10 - 100 ppm; Moore et al., 1998; Kegley, 2007), which shows that this species is more sensitive to acute exposure to high concentrations of propanil than the most sensitive animals specified by PAN. Similarly, the $\mathrm{LC}_{50}$ value of propanil for the common hourglass tree frog (Jayawardena et al., 2010), bog frog and clawed toad (Xenopus laevis) are also below the PAN specified range (Kegley, 2007) indicating that the effect of propanil is more profound in these four species of anurans, and probably in all amphibians in general.

Exposure to pesticides at the ecologically relevant doses had a significant effect on the survival in a dose dependent manner. The highest mortality (64\% at $1 \mathrm{ppm})$ was observed in glyphosate exposed tadpoles followed by chlorpyrifos (61\% at $0.5 \mathrm{ppm})$. The increase in mortality was significantly high in all the exposed concentrations compared to the control group. However, chlopyrifos exposed tadpoles had a consistently high mortality throughout the concentration series. Different pesticides have different targets. Some pesticides are endocrine disruptors interfering with hormonal processes. Pesticides, which are enzyme inhibitors, such as acetylcholine esterase (ChE) inhibitors, interfere with the proper functioning of the nervous system (Hayes et al., 2006). Organophosphorous insecticides such as chlopyrifos and dimethoate are well known ChE inhibitors, which bind with $\mathrm{ChE}$ in animals and disrupt their neural functioning (Hayes et al., 2006). Disrupted ChE activity is known to cause increased mortality, reduced activity, increased vulnerability to predators, and reduced growth of tadpoles (Cowman and Mazanti, 2000). Chlorpyrifos particularly disrupts both cholinergic and adrenergic functions in the nervous system (Suwalsky et al., 2003).This might cause a substantial effect on survival even at very low concentrations. Moreover, Suwalsky et al. (2003) demonstrated that high solubility of chlorpyrifos in lipid medium enhances its interference on the neuroepithelial junction. It affects ion transport across the cell membrane and induces changes in the lipid-protein interface of the cell membrane resulting in heavy mortality (Suwalsky et al., 2003).

Glyphosate and propanil are herbicides targeted to disrupt the photosynthetic pathway and therefore considered to have little effect on animals. However, this study shows that these two herbicides significantly affected the survival, growth and the development of malformations in B. melanostictus. Acute exposure to high concentrations of propanil and chronic exposure to ecologically relevant doses of glyphosate had a high direct lethal effect on this species. In the commercial formulation of glyphosate the added surfactant (POEA) is known to be more toxic than the active constituent, glyphosate (Wan et al., 1989). Even though the current study did not isolate the impacts of the active ingredient glyphosate and the surfactant, laboratory studies have shown that glyphosate alone has a low toxicity while the surfactant can be highly toxic to a variety of taxa including amphibians (Mann and Bidwell, 1999; Lajmanovich et al., 2003; Howe et al., 2004).

Delayed metamorphosis was observed in all the tadpoles exposed to pesticides with a significant elongation of the growth period (tadpole stage). Delayed metamorphosis due to exposure to chemical contaminants has been reported in tadpoles of several species of amphibians. For example, the tadpoles of Hyla arborea upon exposure to dimethoate (Mizgireur et al., 1984) and Hyla chrysoscelis exposed to chlorpyrifos and atrazine (Briston, 1998) have taken a longer period to metamorphose. Exposure to chlorpyrifos, dimethoate, glyphosate and propanil significantly lengthen the time to metamorphose in the tadpoles of $P$. cruciger (Jayawardena et al., 2010). Delayed metamorphosis has a crucial impact on amphibian survival, because they often breed in temporary water bodies, particularly in agricultural and human altered habitats where the water bodies can dry up before the tadpoles complete metamorphosis. Longer the development period, higher the chances of exposure to predators, parasites and other etiologies in the environment leading to increased mortality. Therefore, it is likely that exposed individuals are at a disadvantage under natural conditions and may face threats and indirect mortality as a consequence of delayed metamorphosis. All the exposed tadpoles in previous studies that showed lengthening of development period are smaller in size at the time of metamorphosis (Mizgireuv et al., 1984; Briston, 1998; Jayawardena et al., 2010). It has also been reported that the tadpoles of 
R. sylvatica exposed to glyphosate (Vision $\left.{ }^{\circledR}\right)$ in a conifer plantation showed a reduction in length and weight, compared to unexposed frogs (Glaser, 1998). In contrast, the metamorphs of $B$. melanostictus were larger than those in the control. Even though exposed tadpoles had a longer tadpole period, larger size at metamorphosis could be an advantage for the tadpoles of $B$. melanostictus as bigger size affects the individual's reproduction (Hayes et al., 2006), survival (Shenoy et al., 2009), immunocompetence (Christin et al., 2003; Carey et al., 2009) and ability to escape from predators and defending territories (Bridges, 1999).

The types of malformations observed were mainly axial. Studies on exposure to agricultural contaminants (Ouellet et al., 1997) reported severe limb deformities such as ectrodactyly (missing digit), polydactyly (extra digit), apody (missing foot), ectromely (missing limb) and polymely (extra limb) in amphibians. In the present study $B$. melanostictus exposed to pesticides did not produce severe limb malformations. However, malformations in the spine, such as kyphosis (hunched back) and scoliosis (curvature) were common. Moreover, skin ulcers and oedemas were also observed. Oedemas caused shifting of the centre of gravity resulting in twisting of the body axis, which in turn affected their swimming behaviour. Affected tadpoles were seen swimming upside down, not being able to balance the body while swimming. These oedemas upon rupturing were often fatal. Most of the malformations in the tail region disappeared as the tail was absorbed and these tadpoles metamorphosed into normal adults. Tadpoles of $P$. cruciger exposed to the same chemicals (Jayawardena et al., 2010) and $R$. sylvatica exposed to glyphosate (Vision $\AA$; Glaser, 1998) have shown a similar array of axial malformations where newly metamorphosed frogs had dorsally curved, laterally curved or undulated (like a wave) axial skeleton together with oedemas and abnormal tails. Even though the malformed tadpoles survive to metamorphose under laboratory conditions, they are vulnerable in the wild and are linked with indirect mortality due to increased predation (Sessions \& Ruth, 1990). Hence, the mortality of exposed individuals could be much higher if the results are extrapolated into a field context.

The four pesticides tested in the present study are extensively used to control weeds and pests attacking rice, tea, coconut and other crops in Sri Lanka. Recently, an analysis of water samples from a well with possible exposure to agricultural run-off showed that water contained up to $10 \mathrm{ppm}$ of glyphosate (Roundup®; Navaratne et al., 2009). Water from these wells are used by man for drinking, cooking, bathing and washing clothes, while such habitats provide excellent breeding sites for many frog and toad species. Rice fields are also preferred habitats of amphibians and 18 species have been found breeding in rice fields throughout Sri Lanka (Bambaradeniya, 2000). Unlike other freshwater ecosystems where pesticide run-off is prevalent, rice fields are subjected to direct application of agrochemicals and hence the levels of these chemicals are expected to be much higher in rice fields. The results of this study underscore the importance of investigation of the levels of these agricultural pesticides in freshwater ecosystems.

\section{Acknowledgement}

Authors thank the National Science Foundation, Sri Lanka for financial assistance (Grant No. NSF/ 2005/ EB/02) and P. Samarawickrama, S. Harischandra, N.S. Somaweera and N. Wijethilaka for technical support.

\section{REFERENCES}

1. Alford R.A. \& Richards S.J. (1999). Global amphibian declines: a problem in applied ecology. Annual Review of Ecology and Systematics 30(1):133-165.

2. Bambaradeniya C.N.B. (2000). Ecology and biodiversity in an irrigated rice field ecosystem in Sri Lanka. $P h D$ Thesis, University of Peradeniya, Peradeniya.

3. Berril M., Bertram S., Millivray L., Kolohon M. \& Pauli B. (1994). Effects of low concentrations of forest-pesticides on frog embryos and tadpoles. Environmental Toxicology and Chemistry 13(4): 657-664.

4. Blaustein A.R. \& Wake D.B. (1995). The puzzle of declining amphibian populations. Scientific American 272(4): 56-61.

5. Blaustein A.R., Romansic J.M., Kiesecker J.M. \& Hatch A.C. (2003). Ultraviolet radiation, toxic chemicals and amphibian population declines. Diversity and Distribution 9(2):123-140.

6. Boone M.D. \& Semlitsch R.D. (2002). Interactions of an insecticide with competition and pond drying in amphibian communities. Ecological Applications 12(1): 307-316.

7. Bridges C.M. (1999). Predator-prey interactions between two amphibian species: effects of insecticide exposure. Aquatic Ecology 33(2): 205-211.

8. Bridges C.M. \& Semlitsch R.D. (2000). Variation in pesticide tolerance of tadpoles among and within species of Ranidae and patterns of amphibian decline. Conservation Biology 14(5): 1490-1499.

9. Briston C.A. (1998). Abundance, metamorphosis, development and behavioural abnormalities in Hyla chrysoscelis tadpoles following exposure to three agrochemicals and methyl mercury in outdoor mesocosmos. Bulletin of Environmental Contamination and Toxicology 61(5):154-161.

10. Canadian Council on Animal Care (1993). Guide to the Care and Use of Experimental Animals, volumes 1 and 2. pp.231-234. Canadian Council on Animal Care, Ontario, Canada.

11. Carey C., Cohen N. \& Rollins-Smith L. (1999). Amphibian declines: an immunological perspective. Developmental 
and Comparative Immunology 23(6):459-472.

12. Christin M., Gendron A.D., Brousseau P. \& Menard L. (2003). Effects of agricultural pesticides on the immune system of Rana pipiens on its resistance to parasite infection. Environmental Toxicology and Chemistry 22(5):1127-1133.

13. Cowman D.F. \& Mazanti L.E. (2000). Ecotoxicology of "New Generation" Pesticides to Amphibians. In: Ecotoxicology of Amphibians and Reptiles (eds. D.W. Sparling, G. Linder \& C.A. Bishop). Society of Environmental Toxicology and Chemistry, Pensacola, Florida, USA.

14. Environmental Protection Agency (2006). Probit Analysis, LC50 software program version 1.5. http://www.epa.gov/ nerleerd/stat2.html. Accessed 25 May 2006.

15. Glaser J.D. (1998). Effects of Vision (glyphosate) on progeny of wood frogs exposed in conifer plantations. $M S c$ Thesis, University of Guelph, Guelph, Ontario, Canada.

16. Gosner K.L. (1960). A simplified table for staging anuran larvae with notes on identification. Herpetologica 16(3):183-190.

17. Hayes T.B., Case P., Chui S., Chung D., Haeffele C., Haston K., Lee M., Phoung Mai V., Marjuoa Y., Parker J. \& Tsui M. (2006). Pesticide mixtures, endocrine disruption, and amphibian declines: are we underestimating the impact? Environment Health Perspective 114(1): 40-50.

18. Hayes T.B., Haston K., Tsui M., Hoang A., Haeffele C. \& Vonk A. (2003). Atrazine-induced hermaphroditism at 0.1 ppb in American Leopard Frogs (Rana pipiens): laboratory and field evidence. Environment Health Perspective 111: 568-575.

19. Howe C.M., Berrill M., Pauli B.D., Helbing C.C., Werry K. \& Veldhoen N. (2004). Toxicity of glyphosate based herbicides to four North American frog species. Environmental Toxicology and Chemistry 23(8):1928-1938.

20. World Conservation Union (IUCN) (2006). Global Amphibian Assessment (GAA). http://www. globalamphibians.org. Accessed 15 March 2008.

21. Jayawardena U.A., Rajakaruna R.S., Navaratne A.N. \& Amerasinghe P.H. (2010). Trematode induced malformations in amphibians: effect of infection at pre limb bud stage tadpoles of Polypedates cruciger Blyth. Journal of the National Science Foundation of Sri Lanka 38 (4): 241-248.

22. Jayawardena U.A., Rajakaruna R.S., Navaratne A.N. \& Amerasinghe P.H. (2010). Toxicity of pesticides exposure on common hourglass tree frog, Polypedates cruciger. International Journal of Agriculture and Biology12(5): 641- 648

23. Kegley S.B., Hill B. \& Orme S. (2007). PAN Pesticide Database, Pesticide Action Network North America.www. pesticideinfo.org. Accessed 15 March 2008.

24. Lajmanovich R.C., Sandoval M.T. \& Peltzer P.M. (2003). Induction of mortality and malformation in Scinax nasicus tadpoles exposed to glyphosate formulations. Bulletin of Environmental Contamination and Toxicology 70(3): 612-618.

25. Manamendra-Arachchi K. \& Pethiyagoda R. (2006). Amphibians of Sri Lanka, pp. 99-101, 393-395. World Heritage Trust Publications (Pvt) Ltd., Colombo 8.

26. Mann R.M. \& Bidwell J.R. (1999). The toxicity of glyphosate and several glyphosate formulations to four species of southwestern Australian frogs. Archives of Environmental Toxicology and Chemistry 36(2):193-199.
27. Mazanti L.E., Rice C., Bialek K., Sparling D., Stevenson C., Johnson W.E., Kangas P. \& Rheinstein J. (2003). Aqueous-phase disappearance of atrazine, metolachlor, and chlorpyrifos in laboratory aquaria and outdoor mesocosms. Archives of Environmental Toxicology and Chemistry 44(1):67-76.

28. Meegaskumbura M. \& Manamendra-Arachchi K. (2005). Description of eight new species of shrub frogs (Ranidae: Rhacophorinae: Philautus) from Sri Lanka. Raffles Bulletin of Zoology 12:305-338.

29. Meteyer C.U. (2000). Field guide to malformations of frogs and toads with radiographic interpretations. USGS National Wildlife Health Centre. www.nwhc.usgs.gov/publications/ fact_sheets/pdfs/frog.pdf. Accessed 01 January 2008.

30. Mizgireuv I.V., Flax N.L., Borkin L.J. \& Khudoley V.V. (1984). Dysplastic lesions and abnormalities in amphibians associated with environmental conditions. Neoplasma 31(2): 175-181.

31. Moore M.T., Pierce R.J., Milam C.D., Farris J.L. \& Winchester E.L. (1998). Responses of non-target aquatic organisms to aqueous propanil exposure. Bulletin of Environment Contamination and Toxicology 61(2): 169174.

32. Navaratne A.N., Devasurendra A.M., Magamage C., Dissanayake C.B., Abeyasekara T. \& Athuruliya N.T.C. (2009). Pesticide and pesticide residue analysis of drinking water in Girandurukotte area where chronic kidney disease is prevalent. Proceedings of the $14^{\text {th }}$ Annual Research Sessions of Universityof Peradeniya. University of Peradeniya, Peradeniya, p. 45.

33. Ouellet M., Bonin J., Rodrigue J., DesGranges J. \& Lair S. (1997). Hind limb deformities (ectromelia, ectrodactyly) in free living anurans from agricultural habitats. Journal of Wildlife Diseases 33(1): 95-104.

34. Pethiyagoda R. \& Manamendra-Arachchi K. (1998). Evaluating Sri Lanka's amphibian diversity. Occasional Papers, No.2. Wild Life Heritage Trust, Colombo 8.

35. Rajakaruna R.S., Piyatissa P.M.J.R., Jayawardena U.A., Navaratne A.N. \& Amerasinghe P.H. (2008). Trematode infection induced malformations in the common hourglass tree frog. Journal of Zoology 275(1):89-95.

36. Rajakaruna R.S., Samarawickrama V.A.M.P.K. \& Ranawana K.B. (2007). Amphibian declines and possible etiologies: the case for Sri Lanka. Journal of the National Science Foundation of Sri Lanka 35(1):3-8.

37. Relyea R.A. (2005). The lethal impacts of Roundup and predatory stress on six species of North American tadpoles. Archives of Environmental Contamination and Toxicology 48(3): 351-357.

38. Sessions S.K. \& Ruth S.B. (1990). Explanation for naturally occurring supernumerary limbs in amphibians. Journal of Experimental Zoology 254(1): 38-47.

39. Shenoy K., Cunningham B.T., Renfroe J.E. \& Crowley P.H. (2009). Growth and survival of northern leopard frog (Rana pipiens) tadpoles exposed to two common pesticides. Environmental Toxicology and Chemistry 28(7):1469-1474.

40. Sparling D.W. \& Fellers G.M. (2007). Comparative toxicity of chlorpyrifos, diazinon, malathion and their oxon derivatives to larval Rana boylii. Environment Pollution 147(3):535-539.

41. Sparling D.W. \& Fellers G.M. (2009). Toxicity of two insecticides to California, USA, anurans and its relevance to declining amphibian populations. Environmental Toxicology and Chemistry 28(8):1696-1703. 
42. Sparling D.W. (2003). A review of the role of contaminants in amphibian declines. Handbook of Ecotoxicology (eds. D.J. Hoffman, B.A. Rattner, G.A. Burton Jr \& J. Cairns Lewis Jr), pp. 1099-1128. Boca Raton, Florida, USA.

43. Sparling D.W., Fellers G.M. \& McConnell L.L. (2001). Pesticides and amphibian population declines in California, USA. Environmental Toxicology and Chemistry 20(7): 1591-1595.

44. Stuart S.N., Chanson J.S., Cox N.A., Young B.E., Rodrigues A.S.L., Fischman D.L. \& Waller R.W. (2004). Status and trends of amphibian declines and extinctions worldwide. Science 306(5702):1783-1786.
45. Suwalsky M., Benites M., Norris B. \& Sotomayorc C.P. (2003). The organophosphorous insecticide chlorpyrifos affects the neuroepithelial junction, the bioelectric parameters of the skin of the frog Caudiverbera caudiverbera, and the structure of model cell membranes. Pesticide Biochemistry and Physiology 77(2):44-53.

46. Wan M.T., Watts R.G. \& Moul D.J. (1989). Effects of different dilution water types on the acute toxicity to juvenile pacific salmonids and rainbow trout of glyphosate and its formulated products. Bulletin of Environmental Contamination and Toxicology 43(6): 378-385. 